\title{
$-626-$ \\ Guimarães GP, Monticelli M \\ A FORMAÇÃO DO APEGO PAIS/RECÉM-NASCIDO PRÉ-TERMO E/OU DE BAIXO PESO NO MÉTODO MÃE-CANGURU: UMA CONTRIBUIÇÃO DA ENFERMAGEM ${ }^{1}$ \\ ATTACHMENT FORMATION BETWEEN PARENTS/PRE-TERM NEWBORNS AND/OR LOW BIRTH WEIGHT CHILDREN USING THE KANGAROO MOTHER METHOD: A CONTRIBUTION TO NURSING \\ LA FORMACIÓN DEL APEGO PADRES/RECIÉN NACIDO PRETÉRMINO Y/O DE BAJO PESO EN EL MÉTODO MADRE CANGURO: UNA CONTRIBUICIÓN DE LA ENFERMERÍA
}

\author{
Gisele Perin Guimarães², Marisa Monticelli
}

\begin{abstract}
${ }^{1}$ Dissertação de Mestrado apresentada ao Programa de Pós-graduação em Enfermagem (PEN) da Universidade Federal de Santa Catarina (UFSC), em dezembro de 2006, com apoio financeiro da Coordenação de Aperfeiçoamento de Pessoal de Nível Superior (CAPES).

2 Enfermeira. Mestre em Enfermagem. Membro do Núcleo de Pesquisa em Enfermagem na Educação Popular em Saúde (NEPEPS). Santa Catarina, Brasil.

${ }^{3}$ Doutora em Enfermagem. Professora Associado do Departamento de Enfermagem e do PEN/UFSC. Vice-líder do Grupo de Pesquisa em Enfermagem na Saúde da Mulher e do Recém-nascido. Membro pesquisador do NEPEPS. Orientadora da dissertação. Santa Catarina, Brasil.
\end{abstract}

PALAVRAS-CHAVE: Enfermagem neonatal. Prematuro. Cuidados de enfermagem. Relações familiares.

KEYWORDS: Neonatal nursing. Premature infant. Nursing care. Family relations.

PALABRAS CLAVE: Enfermería neonatal. Prematuro. Atención de enfermería. Relaciones familiares.
RESUMO: Trata-se de relato de pesquisa convergente-assistencial com o objetivo de identificar e analisar os aspectos promotores e complicadores do processo de formação do apego entre pais e filhos pré-termo e/ou de baixo peso durante a prática do Método Mãe-Canguru. Foi desenvolvida na unidade neonatal de um hospital universitário com três casais e quatro recém-nascidos. A coleta de dados deu-se através do processo cuidativo, de julho de 2005 a fevereiro de 2006. A análise envolveu processos de apreensão, síntese, teorização e transferência. Os resultados apontam como principais aspectos promotores: o preparo adequado no pré-natal, o acolhimento no momento do nascimento e a participação ativa no cotidiano neonatal, e como complicadores, a ambigüidade de sentimentos, a falta de compreensão sobre a imaturidade do neonato e a complexa demanda para o cuidado do bebê. Destaca-se o papel da enfermeira como sendo articuladora e tutora do processo de cuidar da aproximação pais-filhos durante a vigência do Método.

ABSTRACT: This is a report of a Convergent-supportive research study that had has its objective to identify and to analyze the promoting and complicating aspects of the bond formation process between parents and premature and/or low birth weight children using the practice of the Kangaroo Mother Method. The study was conducted at the neonatal unit of a university hospital with three couples and four newborns from July of 2005 through February of 2006. The analysis consisted of information gathering, summarization, theorization, and the transferring processes. The results indicated that the main promoting factors were: adequate pre-natal preparedness, comforting at the birth moment, and active participation during the neonatal daily routine. They indicated as complicating factors the ambiguity of feelings, a lack of comprehension about the neonatal child's immaturity, and the complex demands of caring for a baby. The nurse's role is pointed out as the articulator and tutor during the caring and attachment process of parent-child during this method.

RESUMEN: El presente artículo trata de un relato de Investigación Convergente-Asistencial, cuyo objetivo fue identificar y analizar los aspectos promotores y las dificultades del proceso de formación del apego entre los padres y los hijos pretérmino y/o con bajo peso, durante la práctica del Método Madre-Canguro. El estudio fue desarrollado en la unidad neonatal de un hospital universitario con tres parejas y cuatro recién nacidos. La recolección de los datos fue realizada a través del proceso cuidativo en enfermería, en el período de julio de 2005 a febrero de 2006. El análisis se consideraron procesos de percepción, síntesis, teorización y transferencia. Los resultados obtenidos señalan como principales aspectos promotores, los siguientes: la adecuada preparación en el prenatal, la acogida en el momento del nacimiento y la activa participación en el cotidiano neonatal. Como dificultades se pueden señalar: la ambigüedad de sentimientos, la falta de comprensión en relación a la precocidad del neonato y la compleja demanda para cuidar del bebé. Se destaca el papel de la enfermera como la articuladora y tutora del proceso de cuidar de la aproximación de padreshijos durante la vigencia del Método Madre-Canguro.
Gisele Perin Guimarães

Endereço: Av. Osni João Vieira, 237, Ap. 301

88.101-270 - Campinas, São José, SC, Brasil.

E-mail: giseperin@hotmail.com
Artigo original: Pesquisa

Recebido em: 11 de abril de 2007 Aprovação final: 10 de outubro de 2007 


\section{INTRODUÇÃO}

Sabe-se que em todo o mundo nascem anualmente cerca de 20 milhões de crianças pré-termo e/ou de baixo peso". Destas, um terço morre antes de completar um ano de vida. No Brasil, segundo o Ministério da Saúde, ${ }^{1}$ as primeiras causas de mortalidade infantil relacionam-se com as afecções perinatais, dentre elas os problemas respiratórios e os metabólicos, como dificuldades para regular a temperatura corporal. As possibilidades de sobrevivência destes bebês vêm aumentando, associadas a um conjunto de procedimentos cada vez mais especializados, tanto na forma de como está sendo prestada a assistência, como no uso das tecnologias para este fim. ${ }^{2}$

Por outro lado, atualmente, vem-se trabalhando propostas que envolvem a criança, os pais e a família em uma nova perspectiva, que é denominada, inclusive pelas instituições e políticas públicas, como "atenção humanizada". Nesta visão, o principal objetivo é o de respeitar as necessidades, as características e as individualidades, além de promover mudanças que possam ter impacto significativo nas estatísticas mundiais referentes às questões de saúde e sociedade. Assim, para melhor definir, apoiar e padronizar ações similares nas unidades neonatais, o Ministério da Saúde brasileiro lançou, em 05/07/2000, a Norma de Atenção Humanizada ao Recém-nascido de Baixo Peso - Projeto MãeCanguru, ${ }^{3-4}$ que ficou difundido como Método Mãe-Canguru (MMC), sendo hoje uma Política Nacional de Saúde para esta população.

O Método é definido como "um tipo de assistência neonatal que implica no contato pele-apele precoce entre mãe e recém-nascido, de forma crescente e pelo tempo que ambos entenderem ser prazeroso e suficiente, permitindo, dessa forma, uma participação dos pais no cuidado ao recém-nascido" 1:18 Sua aplicação varia de acordo com o país, sendo que, no Brasil, é utilizado com o objetivo de incentivar a formação do vínculo e do apego entre pais e bebês pré-termo e/ou de baixo peso.

Para os pais, muitas vezes, o fato de ter um bebê que não se aproxima das características idealizadas, além das dúvidas acerca de sua sobrevivência é, muitas vezes, associado a sentimentos de incapacidade, culpa e medo, o que poderá interferir no relacionamento com o filho recém-nascido, mesmo que tal processo não seja plenamente consciente para os pais, afetando diretamente a relação entre eles.

Nesta linha reflexiva, a presente pesquisa, que se consubstanciou na dissertação de mestrado da autora, objetivou identificar e analisar os aspectos promotores e complicadores do processo de formação do apego entre os pais e os recém-nascidos durante esta prática.

\section{REFERENCIAL TEÓRICO-METODOLÓ- GICO}

Trata-se de uma pesquisa qualitativa do tipo Convergente-Assistencial (PCA), ${ }^{6}$ conduzida de julho de 2005 a fevereiro de 2006, nos turnos matutino, vespertino e noturno, na unidade de neonatologia do Hospital Universitário Polydoro Ernani de São Thiago (HU) da Universidade Federal de Santa Catarina (UFSC).

A PCA é um método que está orientado para a resolução ou minimização de problemas da prática que a enfermeira enfrenta e nas possibilidades de mudança e de introdução de inovações nas práticas de saúde. Consubstancia-se num tipo de investigação que se desenrola de modo concomitante com a prática assistencial de enfermagem, já que sua principal característica é a convergência com essa prática. Deste modo, durante a operacionalização do processo de cuidar, a enfermeira coleta dados, com a finalidade de responder à(s) pergunta(s) de pesquisa. O processo de cuidar passa a ser o meio para se buscar as informações necessárias que irão alimentar as indagações processadas pela pesquisa. ${ }^{6}$

Os sujeitos foram três casais e quatro recémnascidos (já que um casal teve gemelares), que estavam aptos a participarem da prática do MMC no período da pesquisa.

A ancoragem teórica foi feita a partir do Referencial do Apego ${ }^{7}$ e do Modelo de Adaptação, de forma complementar. O primeiro foi escolhido por expressar o conhecimento acerca da formação do afeto entre a tríade mãe-pai-filho, e o segundo, por conter elementos conceituais e operacionais que auxiliam a enfermeira no processo de cuidar, facilitando o percurso em busca do estabelecimen-

\footnotetext{
A Organização Mundial da Saúde (OMS) define recém-nascido pré-termo toda criança nascida viva antes de completar a $37^{a}$ semana de gestação (ou seja, imaturo) e recém-nascido de baixo peso toda e qualquer criança com menos de $2.500 \mathrm{~g}$, independente de sua maturidade. Por outro lado o Método Mãe-Canguru acolhe ambos os recém-nascidos, tanto os pré-termo, quanto os de baixo peso. Entretanto, como nem sempre o bebê de baixo peso é pré-termo, optei por utilizar a expressão "pré-termo el ou de baixo peso" durante o decorrer deste estudo.
} 
to precoce da formação do apego entre os pais e seus recém-nascidos.

A coleta de dados da pesquisa foi realizada durante o desenvolvimento do processo cuidativo em enfermagem, enquanto pais e recém-nascidos pré-termo e/ou de baixo peso praticavam o MMC na unidade neonatal. Tal processo cuidativo constou de quatro etapas: identificação dos modos adaptativos; diagnóstico de enfermagem; estabelecimento de metas, plano e implementação de cuidados; e avaliação. ${ }^{8}$ No decorrer desta metodologia assistencial, de forma sistemática e contínua, utilizaram-se instrumentos para a coleta de dados para a pesquisa, envolvendo basicamente técnicas de observação participante e entrevista focalizada.

$\mathrm{Na}$ observação participante busquei envolverme com os sujeitos em suas ações, sempre com suas aquiescências, porém sem que houvesse qualquer tipo de interferência e realizando esta observação em diferentes turnos (matutino, vespertino e noturno), pois acreditava que poderia haver variação de conduta por parte destes, de acordo com a rotina estabelecida pela unidade em foco. $\mathrm{O}$ recém-nascido era observado constantemente no processo de interação, não só na presença de seus pais, como também na sua ausência e nos cuidados/procedimentos realizados pela equipe de saúde neonatal. Nesta observação focalizei todos os modos de adaptação que envolvia o comportamento dos pais com relação a aproximação junto ao seu filho, tendo como foco de atenção os seguintes tópicos: de que forma este contato ocorreu (verbal, tato, expressões de carinho ou apenas o de prestar cuidados de conforto...); em que momento foi mais efetiva esta aproximação; quem mais se destacou (pai/mãe) nesta aproximação; interferências e facilidades observadas no decorrer deste processo, dentre outros.

Posteriormente, ou mesmo no decorrer do processo de observação, de acordo com a necessidade, eu complementava esta primeira fase de identificação dos modos adaptativos, lançando mão da técnica de entrevista, para que houvesse maior aprofundamento, polimento, confirmação ou descarte de interpretações e sentidos, sendo que os sujeitos envolvidos eram comunicados previamente, respeitando os princípios legais e éticos da assistência e da investigação. Tais entrevistas foram sendo desenvolvidas sob a forma semi-estruturada e de aspecto informal, tendo como objetivo a complementação da observação, utilizando o próprio campo de observação para a aplicação da mesma.
Após o desenvolvimento dos processos cuidativos com os sujeitos do estudo iniciou-se a organização, interpretação e análise dos dados obtidos, seguindo-se os quatro processos genéricos de análise qualitativa sugeridos pela PCA, ${ }^{6}$ ou seja, apreensão, síntese, teorização e transferência, que resultou um elenco de categorias e subcategorias que serão apresentadas a seguir. $\mathrm{Na}$ apreensão buscou-se o conjunto de informações obtidas durante o processo de cuidar, visando à incorporação das idéias principais sobre os aspectos facilitadores e complicadores da formação do apego. Na síntese, avaliaram-se subjetivamente as associações e variações das informações, relevando os dados mais significativos do estudo. $\mathrm{Na}$ teorização buscou-se interpretar os dados levantados, em associação com a fundamentação teórica adotada e na transferência, atribuíram-se significados aos resultados, além de contextualizá-los sem generalizá-los, respeitando os princípios fundamentais que sustentam estudos qualitativos desta natureza. ${ }^{6}$

Respeitando os princípios éticos, os pais participaram voluntariamente e assinaram o Termo de Consentimento Livre e Esclarecido. O projeto foi aprovado pelo Comitê de Ética em Pesquisa em Seres Humanos da UFSC, sob o parecer No 392/05.

\section{RESULTADOS E DISCUSSÃO}

\section{Aspectos promotores da formação do apego}

\section{Categoria 1 - o percurso vivenciado antes de chegar à unidade neonatal}

A formação do apego entre pais e filhos antecede o momento de hospitalização para o nascimento propriamente dito. O desejo comum dos casais deste estudo em expandir suas famílias, para o presente ou para um futuro não tão distante, parece trazer aos casais a sensação de estarem "mais completos” como família e conscientes das responsabilidades atribuídas nesta nova etapa de suas vidas, passando a procurar um serviço de saúde que, em suas concepções, seja adequado para o enfrentamento das necessidades que advirão do processo gravídico. Os casais com os quais convivi na condução deste estudo jamais esperavam e sequer imaginavam que pudesse vir a ocorrer um nascimento pré-termo no momento em que recebiam a notícia da gravidez. Assim, a preocupação, no início da vivência da gestação, girava em torno da necessidade de um pré-natal bem assistido. Percebi que isso fortalecia os elos entre o homem e a mulher, que passavam a se unirem mais e a inserirem o 
novo ser gerado à unidade familiar. Esta sensação de acolhimento descrita por eles me levou a interpretar que aí se iniciava algo, de modo precoce, que poderia associar à promoção do processo de afeiçoar-se ao filho que estava por chegar.

Mais tarde, com os sinais de parto prematuro, os casais procuravam então uma maternidade a fim de que a mulher pudesse ser avaliada e provavelmente encaminhada para o centro obstétrico. Este local, segundo seus depoimentos, precisaria ter condições tecnológicas e humanas adequadas para receber a situação adversa, assegurando o parto e o nascimento com a atenção merecida. Diante disso, a totalidade das famílias do estudo acorreu à maternidade do $\mathrm{HU}$, por ser considerada mais qualificada para a assistência à mulher e ao recém-nascido pré-termo e/ou de baixo peso. Observei que, para a maioria dos casais, o fato de estar preparado para o evento precoce favorecia a aceitação mais rápida da situação (como por exemplo, verbalizando: a gente já esperava por esta correria), o que ajudava a promover a aproximação com a criança e entre o homem e a mulher, mesmo diante da necessidade quase unânime de encaminhamento do recém-nascido à unidade neonatal, em transporte de urgência.

Esta categoria abrange as subcategorias denominadas de: a) preparo do casal para enfrentar as mudanças de rumo na gravidez - em que se percebe que o casal que foi preparado para o parto prematuro apresenta menos conflitos e necessidades de realinhar os sentimentos provenientes deste tipo de experiência; b) presença do acompanhante no centro obstétrico - onde argumenta-se que a possibilidade das gestantes serem acompanhadas durante todo o período do pré-parto e parto no centro obstétrico é considerado por elas um fator determinante para a segurança das mesmas, garantindo total apoio neste momento de intensa expectativa; e c) olhar, tocar, sentir o bebê no momento do nascimento: do filho idealizado ao filho real - onde os pais revelam que mesmo sendo curto o tempo de aproximação entre eles e o filho, confirmam a relevância desta interação. É o momento de sentirem-se pertencentes um ao outro, de identificarem-se, de (re)conhecerem-se e de transmitirem ao recém-nascido segurança e afeição, ainda que por um pequeno lapso de tempo.

\section{Categoria 2 - a atenção e o acolbimento da equipe neonatal}

Nesta categoria, a idéia central da discussão é refletir a respeito de como está sendo oferecido o acompanhamento aos casais pelos profissionais $\mathrm{da}$ unidade neonatal para que, juntos, equipe e pais, possam lutar rumo aos mesmos ideais. Neste sentido, os casais argumentam que precisam se sentir acolhidos e perceberem que são alvo da atenção merecida por parte da equipe neonatal. Para isso explicitam, a cada um dos profissionais, a importância de que os mesmos favoreçam meios para "que o tempo passado em conjunto seja realmente significativo para ambos" 9:170 Afinal, pelo que pude perceber na pesquisa, a equipe de saúde neonatal torna-se um grande e forte pilar que sustenta quase todas as circunstâncias que possam vir a estar presente no cotidiano dos pais que ali estão em decorrência da necessidade de internação do pequeno bebê.

Por sua vez, as subcategorias referentes a este tema surgem como: a) o cuidado "cuidadoso" da equipe gerando segurança para os pais - que vem pontuar a forma como os pais e os bebês se sentem recebidos pelos profissionais. $\mathrm{O}$ que os casais buscam é que o cuidado não seja apenas realizado como obrigação e meramente técnico, mas que esteja aliado a um gesto de carinho, uma voz suave e um toque seguro. Além dos pais esperarem este tipo de comportamento do cuidador para com a criança recém-nascida, eles também têm a expectativa que este cuidado se estenda a eles próprios, já que estão submetidos a tantas e inesperadas tensões, principalmente nos primeiros dias pós-parto; b) intercâmbio de informações entre a equipe e os pais acerca das condições clínicas do recém-nascido - nesta subcategoria, a idéia central está relacionada à necessidade que os pais têm de saberem cada passo da internação, a fim de que possam participar e terem maior consciência dos progressos do filho, assim como a necessidade de serem informados sobre a realização de qualquer intervenção técnica. Tais estratégias na percepção dos casais, ajudam a garantir a participação materna e paterna direta nos cuidados e na prática do MMC, favorecendo mais precocemente o vínculo com a criança; e c) sempre tem um que dá mais atenção: referência profissional durante a hospitalização - mostra a necessidade que os pais têm de adotar um "facilitador" que esteja inserido no ambiente neonatal como referência, para que possam obter informações sobre o bebê, de forma mais segura e direcionada, para solicitarem algo, tirarem dúvidas e até mesmo serem ouvidos em seus desabafos. A enfermeira neonatal surge neste contexto como preferência dos pais para exercer este papel, sobressaindo-se na função tutorial de 
acompanhamento continuado durante o tempo que durar a internação.

\section{Categoria 3 - a participação ativa no cotidiano da unidade}

Aos poucos, o convívio diário dos pais no ambiente neonatal e as interlocuções que ocorrem com os profissionais da equipe vão enfraquecendo a sensação de estranhamento, fazendo com que o cenário tenha o seu "peso" diminuído. Para os casais, o que realmente importa é que, com o decorrer do tempo, consigam ultrapassar as fragilidades iniciais, entrando e saindo da unidade da forma mais natural possível; entretanto, segundo seus depoimentos, isso não se dá de uma hora para outra, mas requer paciência, compreensão e atitudes pró-ativas da equipe neonatal.

Mesmo que mergulhados em sentimentos ainda ambivalentes e cerceados pelo futuro incerto, o pai e a mãe do neonato reforçam o desejo de se sentirem "livres" para circular nas dependências da unidade (talvez a única "liberdade" que realmente possam desfrutar no atual momento) e, em complementaridade, que possam ter o direito de permanecerem com a criança o tempo que acharem necessário e prazeroso. Em suas percepções, estes são dois aspectos promotores do apego com a criança, uma vez que auxiliam no entendimento das suas necessidades e os ajudam a exercitar a paternagem e a maternagem, preparando-os para o momento do retorno ao domić́lio.

As subcategorias envolvidas neste tema são as seguintes: a) ter liberdade para ir e vir no ambiente neonatal - que diz respeito à satisfação dos pais frente à flexibilidade dos horários, bem como a autorização expressa e aceita por todos os profissionais quanto às suas presenças na unidade de internação neonatal, sem que haja obstáculos para suas idas e vindas. Estes são princípios que facilitam o apego, pois ambos expressam sentimentos de acolhimento e, sobretudo, expressam que a mulher e o homem não precisam pedir permissão para a equipe para que sejam "pai" e "mãe". São atitudes que os levam a sentimentos de pertencimento no cotidiano assistencial, ou seja, a sensações de inclusão, e não de afastamento; b) ter a possibilidade de ficar junto da criança em tempo integral ajuda a entender suas necessidades e seus progressos - esta subcategoria ajuda a entender que o recém-nascido pré-termo e/ou de baixo peso tem especificidades e singularidades que só poderão ser compreendidas pelos pais a partir do momento em que estes conseguirem superar os sentimentos e sensações do parto prematuro, passarem a aceitar a situação atual e tiverem o compromisso de ficar junto ao filho, superando gradativamente todo o processo de internação e produzindo então respostas adaptativas efetivas.

\section{Categoria 4 - a troca de experiências com outros pais que vivenciam situações similares}

Muitas vezes o casal acredita que a vivência do parto e nascimento prematuros é algo bem particular, ou seja, que só acomete à sua família. Esta percepção é construída a partir das sensações de medo e apreensão geradas pelo acontecimento inesperado e incerto que, por períodos variados, de certa forma, dilui os sonhos e transforma a realidade em um fardo pesado demais para se superar. Porém, ao ingressarem na unidade neonatal, paulatinamente, começam a perceber que esta realidade também faz parte da vida de tantas outras famílias, e então, ao perceberem que possuem "parceiros", o pai e a mãe prematuros parecem conquistar força renovada para lidar com a situação e, aos poucos, dialogando com esses pares, são levados a uma melhor condição de aceitação e superação das frustrações, tornando o dia-a-dia mais ameno.

\section{Categoria 5 - a oportunidade de (re) conbecer-se no papel de mãe, de pai e de filbo}

Certamente os pais sabem de suas responsabilidades e atribuições, mas muitas vezes isto fica ofuscado pelo temor de não conseguirem dar conta daquele bebê que ali está e que difere por completo do esperado e planejado por eles. Neste caso, os pais podem até imaginar as necessidades da criança, porém não conseguem trabalhar com seus sentimentos, uma vez que estes contradizem um sonho. Surge então a necessidade de reorganizarem seus planos, postergando a volta para casa e permanecendo por um período mais longo dentro do hospital.

Para a maior parte dos casais com os quais trabalhei foi difícil aceitar a chegada precoce do recémnascido, exceto um casal que devido a gemelaridade vinha se preparando para a chegada antecipada dos bebês; mesmo assim o pai e a mãe sofreram frente à necessidade de não poderem se manter tão próximos como planejavam. Somente a partir do momento em que identificavam melhor a situação e passavam a fazer parte dela é que conseguiam assumir a maternagem e a paternagem, expressos através do 
cuidado direto à criança, e pela iniciativa do casal em praticar o MMC mais efetivamente.

Fazem parte desta categoria, as subcategorias: a) responsabilizar-se pelo cuidado direto à criança - em que se ressalta que o papel exercido pelos pais durante todo o período de adaptação pós-natal é um ensaio para que realmente compreendam as múltiplas fases que o bebê pré-termo e/ou de baixo peso vai passar. Este exercício, também de certa forma precoce, exige um redimensionamento na forma com que os pais são inseridos na unidade neonatal e, mais que isso, como são levados a se relacionarem com o filho, não apenas de forma a manifestarem expressões faciais ou orais de carinho e afeição, mas como executores de cuidados aos mesmos, tornando-se um preditivo para a convivência no contexto domiciliar; b) "colar-se" ao filho: o contato corporal ajudando a superar a sensação de que a criança "é quase nada" - em que mostra que quando aos pais é oferecida a oportunidade de realizarem o contato pele-a-pele com o pequeno bebê, é como se estivessem conseguindo findar o processo gestacional que foi bruscamente interrompido. Percebe-se que o corpo e seus movimentos são aliados importantes para a troca de sentimentos entre pais e filho, pois o contato corporal transfere desde emoções comuns, como também aquelas com maior complexidade, através do calor transferido do adulto para o bebê. Quando os pais se disponibilizam a ter o filho em seus braços é porque possivelmente já superaram algumas dificuldades e estão conseguindo maior aproximação com a criança; c) ser chamado pelos membros da equipe de mãe e de pai - isto representa, para eles, a denotação de suas responsabilidades e compromissos, além de reafirmarem a si mesmos, de forma subjetiva, que aquele bebê que está dentro $\mathrm{da}$ incubadora lhes pertence. Os pais que têm seu filho pré-termo parecem necessitar ainda mais desta denominação, por não se sentirem muitas vezes prontos para tal experiência. Com o decorrer das aproximações eles acabam se acostumando com a situação e passam a aceitar mais facilmente esta relação de pai-filho, mãe-filho, acreditando ser um modo carinhoso que a equipe tem de se comunicar com o casal, tornando mais determinante e próximo o convívio; d) o aleitamento materno como elo de aproximação mãe-pai-filho - esta subcategoria revela que poder amamentar o bebê pré-termo e/ou de baixo peso, para os pais, configura-se num avanço do processo de internação. A prematuridade é um fator determinante que distancia consideravelmente o início da sucção do neonato diretamente no seio materno, conforme ocorreu com todos os recémnascidos participantes do estudo. Geralmente a rotina dispensada a esses bebês era de iniciar a alimentação com o leite materno via sonda, sendo que posteriormente, por seringa, oferecendo então o leite através de estímulos de sucção nutritiva realizados, na maioria das vezes, pelo pai ou pela mãe para, mais à frente, estando mais amadurecido e clinicamente em condições, o bebê ser levado ao seio para ter os primeiros contatos com o leite saindo diretamente das mamas maternas.

Para as mulheres, principalmente, este tão sonhado momento era esperado com muita expectativa, já que teriam finalmente o contato físico aguardado, o afeto sem limites e poderem cumprir com uma das únicas funções exclusivamente materna: o ato de amamentar. Para as puérperas deste estudo a amamentação "eleva o ego" e contribui diretamente para o apego concreto com o filho.

\section{Aspectos complicadores da formação do apego}

\section{Categoria 1 - dificuldade inicial para ultrapassar o desafio de serem pais prematuros}

As dificuldades começam a surgir quando o homem e a mulher sentem-se de mãos atadas por não terem nada a fazer e ter que aceitar a situação da prematuridade. Os primeiros conflitos que surgem estão relacionados aos sentimentos variados que atingem o casal, talvez mais intensamente à mulher, em decorrência do pós-parto, um período considerado crítico e sensível. Além de todos os sentimentos negativos e temerosos que cercam a expectativa do evento antecipado (ainda que de pleno conhecimento), como o desapontamento e a frustração por não poderem ter um filho "normal, como os outros", é relevante acrescentar que os casais têm seus desejos diluídos pelas características específicas da criança prematura e pelo ambiente impactante da UTI neonatal. Tais sensações, aliadas às demais demandas pós-natais, acabam dificultando o processo de aproximação entre eles e o bebê, postergando certamente "a troca” entre a tríade.

Como subcategorias são apontadas as seguintes: a) sentimentos de culpa, medo e insegurança com relação ao parto e nascimento prematuros - esta subcategoria destaca o processo de luto como sendo algo já inconscientemente esperado, mostrando mesmo que todos os sentimentos negativos e todas as difi- 
culdades dos pais de se adaptarem à nova realidade são inevitáveis. Porém, durante o decorrer desta pesquisa ficou evidenciada a necessidade da equipe conduzir a família em cada etapa da internação, reaproximando-os da criança e incentivando os pais, individualmente e/ou coletivamente, a superarem diariamente suas dificuldades; b) desapontamento frente à impossibilidade de acolherem o filho ao nascer - ressalta que no pensamento dos pais esse momento se configura como sendo um período de isolamento entre eles e o bebê, em que lhes é retirada a possibilidade de tocarem e cortejarem a criança, fazendo perder todo o sentido do preparo para o nascimento, de acolhimento dos primeiros minutos de vida daquele ser que foi gerado, na maioria das vezes, com tanto amor e carinho. A separação da tríade faz aumentar os questionamentos relacionados à sobrevivência e exacerba sentimentos negativos, como os de ansiedade e insegurança.

\section{Categoria 2 - equipamentos e ações da equipe neo- natal frustrando a aproximação pai-mãe}

Os estímulos não surgem apenas do maquinário e seus apetrechos, mas também das mãos do cuidador que realiza procedimentos especializados e quase sempre promotores de dor no bebê. É comum esta mesma equipe de saúde neonatal assumir por completo todos os cuidados do recém-nascido, tendo muitas vezes, certo poder sobre o mesmo. Quando isto acontece, os pais começam a acreditar que ali, dentro daquele ambiente, somente os profissionais é que podem e devem cuidar, acolher e suprir as necessidades do neonato, cabendo a eles apenas observar de longe como tudo acontece no dia a dia. Torna-se difícil para estes casais se sentirem realmente mãe e pai da criança, considerando a dificuldade e o pouco estímulo que eles têm de colocar em prática a maternagem e a paternagem tão esperada. Essas atitudes profissionais afastam cada vez mais os pais de suas funções, dificultando a vinculação pai-mãefilho, sendo um grande obstáculo a ser vencido no decorrer na internação neonatal.

As subcategorias relevantes mostram: a) a incubadora vista como barreira - denotando que, na percepção dos pais, aquela "caixa aquecida", conforme seus próprios depoimentos, é uma intrusa na relação, embora reconheçam seus benefícios mais imediatos. Esta subcategoria é pródiga em revelar os sentimentos ambivalentes dos pais, entre a compreensão da necessidade da tecnologia e o desejo de poupar o filho da dor e do desconforto; b) atitudes da equipe de saúde durante a realização de procedimentos dolorosos no recém-nascido gerando ansiedade e 'dor' também nos pais - que enfatiza que a perversidade da questão não está no fato da sensação dolorosa propriamente dita, já que alguns procedimentos são promotores deste sintoma, pela reação fisiológica aos estímulos dolorosos neonatais, mas está ligada, muitas vezes, a certo descaso da equipe com relação à utilização de técnicas de contenção da dor, ocorrendo o mesmo com relação ao convite aos pais para que participem de momentos como esses; c) profissionais deixando de oportunizar o exercício da maternagem e paternagem - nesta subcategoria justifica-se que o fato da rotina hospitalar permitir a presença dos pais na unidade neonatal não significa suas inclusões no processo de cuidar e que possam contemplar os exercícios sociais dos papéis de “mãe" e de "pai”. É preciso que os profissionais transfiram para os pais esta responsabilidade e possibilidade de estarem mais próximos da criança.

Categoria 3 - desconbecimento e inabilidade dos pais com relação à imaturidade do recém-nascido para iniciar e manter o processo de amamentação

Diferente de um bebê à termo, a natureza e a origem do apego entre pais e filho pode ficar comprometida quando o neonato é imaturo. Esta singularidade é percebida quando se trata de bebês pré-termo e/ou de baixo peso, sendo visível o grau de imaturidade do reflexo de sucção apresentado por eles, principalmente ao iniciarem a sucção direta no seio materno. A criança tem dificuldade de abocanhar o mamilo, não consegue fazer o movimento de língua, não tem força para extrair o leite, não tem coordenação motora, além de não conseguir se manter acordada para mamar. Quando os pais desconhecem, não compreendem as singularidades do bebê imaturo, ou são ainda inábeis para desempenhar certos procedimentos durante a amamentação, torna-se um aspecto muito forte para afastarem-se do filho ou então para aproximarem-se com a segurança desejada e requerida.

\section{Categoria 4 - entre a vontade de permanecer na instituição e a saudade de casa}

A permanência prolongada no ambiente hospitalar gera alguns conflitos para os casais, frente à ambigüidade dos sentimentos, da vontade de perma- 
necer na instituição e a saudade que têm de casa, dos outros filhos e de seus familiares. Estes sentimentos ficam mais aflorados quando a mulher recebe alta da maternidade e precisa permanecer no hospital em decorrência da internação do recém-nascido que não tem previsão alguma de receber alta da unidade neonatal. Para os casais deste estudo o sofrimento era mais intenso pelo fato de todos residirem fora da cidade, em outras localidades do interior do Estado, longe do seu reduto, e ainda, indiretamente, serem privados de receber visitas diárias de familiares e da rede social de convívio diário.

\section{Categoria 5 - múltiplas, intensas e complexas de- mandas para cuidar do bebê}

O processo de se tornarem pais de bebê prétermo faz com que o homem e a mulher se deparem com diferentes transformações que os incitam a somarem responsabilidades e compromissos, levando muitas vezes à fadiga corporal e mental, frente às múltiplas, intensas e complexas demandas para cuidar do filho, além de todas as alterações hormonais que a mulher está sujeita, em face da vivência puerperal. Conseguir elaborar toda função que a maternidade e a paternidade impõem, exige um grande aprendizado nas vivências diárias no contexto de uma unidade neonatal.

Confirma-se que a tarefa de tornar-se mãe e pai é constituída por diferentes fatores, dentre eles, aqueles referentes às identificações em que o homem e a mulher tentam colocar em prática os modelos parentais e os padrões culturais recebidos na infância, o emocional, e os conflitos frente ao significado de ter um bebê que requer cuidados mais específicos. ${ }^{10}$ Nos íntimos movimentos de cuidar e pesquisar pude perceber o quão conflitante e transformadora é a tarefa de ser pai e mãe de um bebê pré-termo e/ou de baixo peso e as especificidades que são exigidas para o exercício do cuidado a esses bebês. Ao associar as falas, os comportamentos e as expressões, estando bem próxima destes casais, e acompanhando o íntimo e complexo desafio de suas trajetórias diárias, percebi como é desgastante o ir e vir para assumir "pra valer" as atribuições que a situação evoca. Este contexto, aliado às alterações biopsicoemocionais do pós-parto, principalmente para a mulher, se traduz em fortes exigências que, se não forem percebidas com sabedoria e discernimento pela equipe, poderão ser uma base geradora de ansiedades redobradas na situação da prematuridade.

\section{Categoria 6 - insegurança dos pais ao levar o filbo} para casa

A ansiedade e a vontade que o bebê fique bem e atinja o peso necessário para a alta hospitalar é esperada pelos pais desde o momento em que o filho nasce. Com o passar dos dias de internação este desejo aumenta e as expectativas para receberem a tão esperada notícia se concretiza. Para os casais participantes deste estudo, a prévia da alta hospitalar foi dada com aproximadamente uma semana antes do dia real, referida por eles como "liberdade". Porém, esta tal "liberdade" vinha acompanhada de sentimentos de insegurança com relação ao desempenho materno e paterno no âmbito domiciliar. Afinal, em suas casas são eles que terão que dominar todas as situações inesperadas que porventura vierem a acontecer.

Assim, não se pode negar que a notícia da alta torna-se um verdadeiro desafio para o homem e para a mulher. Afinal, foram muitos e longos dias dentro da unidade neonatal, ainda que com uma equipe neonatal qualificada durante todas as horas do dia e da noite, garantindo a sobrevivência do recém-nascido e dando suporte para os seus requerimentos mais sutis. Percebi que durante o período de internação o anseio dos pais estava mais voltado para movimentos de cuidar, se aproximarem e se afeiçoarem ao filho, sendo que pouco vislumbravam a necessidade de ter conhecimentos específicos sobre como agir mediante alguma emergência com o bebê. Esta perspectiva aparecia somente mais tarde e, quase sempre, imersa nos sentimentos ambíguos de felicidade e ansiedade diante da realidade do "ir para casa". A literatura tem abordado atualmente que "é normal" que os pais sintam tais preocupações, mas precisam ser informados de que o apoio a eles e ao filho não ficará limitado às paredes hospitalares. ${ }^{1-2}$

O acompanhamento e o desenvolvimento do bebê em nível ambulatorial são assegurados pela própria instituição, lembrando que todos os bebês que são ingressos no MMC recebem alta precoce, realizando a terceira etapa do Método no domicílio, ou seja, recebem alta do ambiente neonatal, mas não do acompanhamento mensal, até que atinjam o peso de 2.500 gramas. O importante desta última fase do MMC é que os pais assumam a essência do cuidado ao filho, que se estimule a continuação do aleitamento materno exclusivo e se continue fortalecendo o vínculo familiar. ${ }^{11-12}$

Assim, após tanto preparo, seguido de muitas expectativas, é chegada a hora de irem para suas 
casas. Este momento é saudado pelos casais com muita felicidade, euforia e pressa para arrumarem o quanto antes suas bagagens e poderem finalmente se "despedir" da equipe, de outros casais e da unidade, deixando para trás uma etapa dolorosa de suas vidas, mas que certamente atribuiu outros valores à experiência de ser pai e de ser mãe.

\section{CONSIDERAÇÕES FINAIS}

Dentre os achados nesta pesquisa, relativos aos aspectos promotores e complicadores da formação do apego, ficaram destacadas as percepções dos pais a respeito da aproximação precoce com o filho nascido pré-termo e/ou de baixo peso durante a prática do MMC, denotando como é dificultosa e complexa essa aproximação. Durante a fase de duração da hospitalização coexistem muitos conflitos e sentimentos ambíguos, desde culpa e medo, até esperança pela sobrevivência de seus bebês, além de todos os comportamentos imaturos que o neonato apresenta e que muitas vezes não são esperados ou bem compreendidos pelos pais.

É notório que o MMC é uma proposta eficiente e aproximadora entre os pais e seus filhos, pois proporciona meios para se alcançar o apego de forma mais harmoniosa e duradoura. Porém, durante a convivência com estes casais, percebi que, ao mesmo tempo em que é prazeroso estar em contato pele-a-pele com o pequeno bebê, esta prática gera certa preocupação quando relacionada a todas as responsabilidades atribuídas, principalmente ao papel materno, particularmente no que se refere à ordenha do leite e à intensa lida diária em torno desse manejo.

É importante também destacar, como resultado da pesquisa, que os pais que fizeram parte deste estudo expressaram como se sentiram bem ao chegarem à unidade e terem sido recebidos pela equipe de saúde neonatal de maneira singular e acolhedora, além de terem sido orientados sobre a opção de se inserirem na prática do MMC. Também apareceu como ponto forte o fato dos casais se identificarem mais com um determinado profissional, particularmente a enfermeira da unidade, apoiando-se neste como um amparo seguro para o caminhar dentro do ambiente neonatal, durante todo o período da hospitalização. Esta referência mostrou-se imprescindível para os pais dos bebês pré-termo devido à necessidade de se expressarem, serem compreendidos, serem guiados, auxiliados e poderem pedir (e obter) conselhos para a tomada de algumas decisões. Nestas situações também deixaram claro que precisavam que este profissional pudesse ser a referência para as relações afetivas entre a tríade (mãe-pai-filho).

Entretanto, algumas dificuldades se fizeram presentes, sendo consideradas como complicadoras ou dificultadoras da formação do apego. A assistência pré-natal despreparada, sem dúvida, tornou-se um fator complicador no que diz respeito aos comportamentos apresentados pelos casais, principalmente relacionado às características físicas da criança, aos aspectos emocionais frente à impossibilidade de terem o filho em seus braços no nascimento, ao ambiente neonatal e à hospitalização. Sentiam-se amedrontados com os equipamentos utilizados na unidade neonatal, e sempre dependentes de alguém que os ajudassem a colocar o bebê em contato pele-a-pele.

O impacto do bebê "real” (o que está aí), em contraste com o "ideal" (aquele que era projetado), principalmente com relação às suas características físicas e comportamentais, gerou nos casais sentimentos ambivalentes, ficando difícil para eles perceberem, naquela criança, a realização dos seus sonhos. A saúde instável dos bebês apresentou-se como mais um fator complicador nas aproximações entre os pais e os filhos, sendo esta uma questão reiterativa durante todo o período da internação.

Além disso, a não permanência no ambiente hospitalar de forma contínua e a multiplicidade de tarefas e papéis do homem e principalmente da mulher-puérpera-mãe, seja pelo valor que imputam ao seu papel, seja pelas demandas externas da família e da equipe, também foram apontados como intervenientes no processo de formação do apego durante a prática do MMC.

Os achados desta pesquisa apresentam relevâncias múltiplas, tornando-se determinantes para o aprimoramento das práticas assistenciais, relacionadas ao atendimento dos pais e bebês hospitalizados no ambiente neonatal, visando às especificidades desta clientela, assim como o caminho para a formação e manutenção dos processos afetivos entre a família e o recém-nascido pré-termo e/ou de baixo peso. Do ponto de vista do ensino em enfermagem neonatal, busca facilitar a compreensão de educandos e educadores com relação ao período de internação da tríade, fazendo com que percebam o ambiente neonatal, a prática do MMC e seus participantes como uma intrincada rede que entrelaça aspectos promotores $\mathrm{e}$ complicadores, e que acompanha a prematuridade, 
necessitando de intervenção e acompanhamento direto da equipe de saúde neonatal.

Deste modo, percebi, enquanto enfermeirapesquisadora, que cabe a nós profissionais, compreendermos as necessidades de cada casal e indicar o melhor caminho a ser percorrido. A enfermeira, nesta equipe, tem o papel de ser a articuladora e tutora do cuidado "cuidadoso", não só com relação à interação dos pais com a criança, mas também dos diversos elementos da equipe com cada um dos seres humanos que integram a unidade familiar, planejando e desenvolvendo ações para que os pais possam contribuir no cuidado de seu filho e, aos poucos, adquirirem independência no decorrer das transformações diárias. Os pais, portanto, nos mostram que a relação afetiva deles com os filhos dependem, em algum grau, da interação que existe entre eles e a equipe, já que uma relação frágil (ou seja, "superficial” com os integrantes) poderá gerar uma dificuldade ainda maior nas ligações afetivas, levando os mesmos a agravarem seus medos e inseguranças diante da experiência da hospitalização. Essa referência fortalece a idéia já colocada por alguns autores, ${ }^{11-13}$ de que a equipe constitui uma fonte de apoio formal para os pais.

\section{REFERÊNCIAS}

1 Ministério da Saúde (BR), Secretaria de Políticas de Saúde, Área de Saúde da Criança. Atenção humanizada ao recém-nascido de baixo peso: método mãe canguru, manual do curso. Brasília (DF): MS; 2002.

2 Duarte ED, Sena RR. Cuidado mãe-canguru: relato de experiência. Rev. Mineira Enferm. 2001 Jan-Dez; 5 (1/2): 86-92.

3 Ministério da Saúde (BR), Secretaria de Políticas de
Saúde. Área de Saúde da Criança: acompanhamento do crescimento e do desenvolvimento infantil. Brasília (DF): MS; 2002.

4 Joaquim MCM. Como o Brasil trabalhou o método mãe-canguru. Bol. Inform. Método Mãe-Canguru 2003 Abr-Jun; 8: 2.

5 World Health Organization, Depatment of Reproductive Health and Research. Kangoroo mother care: a practical guide 2003. Geneva (SZ): WHO; 2003.

6 Trentini M, Paim L. Pesquisa convergente-assistencial: um desenho que une o saber fazer e o saber pensar na prática assistencial em saúde-enfermagem. 2a ed. Florianópolis (SC): Insular; 2004.

7 Bowlby J. Apego e perda: apego. v. 1. 3a ed. São Paulo (SP): Martins Fontes; 2002.

8 Roy SC. Introduction to nursing an adaptation model. New Jersey (USA): Prentice-Hall; 1984.

9 Monticelli M, Elsen I. Quando o tempo narrativo ultrapassa o tempo da clínica: um modo de cuidar em enfermagem no período pós-natal. Rev. Texto Contexto Enferm. 2005 Abr-Jun; 14 (2): 167-76.

10 Alonso ILK. Luzes e sombras no ritual do encontro entre o universo profissional e o mundo da intimidade familiar: a intervenção profissional na saúde da família em âmbito domiciliar [tese]. Florianópolis (SC): UFSC/PEN; 2003.

11 Borges MLSF. Função materna e função paterna, suas vivências na atualidade. [dissertação]. Uberlândia (MG): UFUB/Programa de Pós-Graduação em Psicologia; 2005.

12 Cardoso ACA, Romiti R, Ramos, JLA, Issler H, Grassiotto C, Sanches MTC. Método mãe-canguru: aspectos atuais. Pediatria 2006; 28 (2): 128-34.

13 Lamego DTC, Deslandes SF, Moreira MEL. Desafios para a humanização do cuidado em uma unidade de terapia intensiva neonatal cirúrgica. Ciência Saúde Coletiva 2005 Jul-Set; 10 (3): 669-75. 